\title{
Proportion of bacterial isolates, their antimicrobial susceptibility profile and factors associated with puerperal sepsis among post-partum/aborted women at a referral Hospital in Bahir Dar, Northwest Ethiopia
}

\author{
Alemale Admas', Baye Gelaw², BelayTessema², Amsalu Worku³ and Addisu Melese ${ }^{1}$ (i)
}

\begin{abstract}
Background: Puerperal sepsis is any bacterial infection of the genital tract that occurs after childbirth. It is among the leading causes of maternal morbidity and mortality especially in low-income countries including Ethiopia. The aim of this study was to determine the proportion of bacterial isolates, their antimicrobial susceptibility profile and factors associated with puerperal sepsis among post-partum/aborted women at a Referral Hospital in Bahir Dar, Northwest Ethiopia.

Methods: A cross sectional study was conducted from January to May 2017 among 166 post-partum/aborted women admitted to Felege Hiwot Referral Hospital for medical services and suspected for puerperal sepsis.. Sociodemographic data and associated factors were collected using structured questionnaire. Bacteria were isolated and identified from blood samples on Trypton soya broth, blood, Chocolate and MacConkey agars following standard bacteriological procedures. The VITEK 2 identification and susceptibility testing system was used to determine the antimicrobial susceptibility profiles of bacterial isolates. Data were entered and analyzed using SPSS version 20. Factors associated with puerperal sepsis were considered statistically significant at $P$-value $<0.05$.

Results: The overall proportion of bacterial isolates among post-partum/aborted women was 33.7\% (56/166); of which $55.4 \%$ was caused by Gram-negative and $44.6 \%$ was by Gram-positive bacteria. The most frequently isolated bacteria were Escherichia coli (32.1\%) from Gram-negatives and Staphylococcus aureus (33.9\%) from Gram-positives. The proportion of other isolates was (7.2\%) for Coagulase Negative Staphylococci (CoNS), (12.5\%) for Klebsiella pneumoniae, (10.7\%) for Acinetobacter baumanni and (3.6\%) for Raoultella ornithinolytica. All isolates of Gram-positive and Gram-negative bacteria were resistant to tetracycline (100\%). The gram negatives show resistance to Cefazolin (72.7\%), Tetracycline (93.9\%) and Ampicillin (100\%). The overall prevalence of multidrug resistance (MDR) was $84 \%$. Women having multiparous parity were more likely to develop puerperal sepsis than primiparous parity (AOR 4.045; 95\% Cl: $1.479-11.061 ; P<0.05)$. Other socio-demographic and clinical factors had no significant association with puerperal sepsis.

(Continued on next page)
\end{abstract}

\footnotetext{
* Correspondence: tedybayegelaw@gmail.com

${ }^{2}$ Department of Medical Microbiology, School of Biomedical and Laboratory

Science, College of Medicine and Health Sciences, University of Gondar,

Gondar, Ethiopia

Full list of author information is available at the end of the article
}

(c) The Author(s). 2020 Open Access This article is distributed under the terms of the Creative Commons Attribution 4.0 International License (http://creativecommons.org/licenses/by/4.0/), which permits unrestricted use, distribution, and reproduction in any medium, provided you give appropriate credit to the original author(s) and the source, provide a link to the Creative Commons license, and indicate if changes were made. The Creative Commons Public Domain Dedication waiver (http://creativecommons.org/publicdomain/zero/1.0/) applies to the data made available in this article, unless otherwise stated. 
(Continued from previous page)

Conclusion: About one third of post-partum/aborted women suspected for puerperal sepsis were infected with one or more bacterial isolates. Significant proportion of bacterial isolates showed mono and multi-drug resistance for the commonly prescribed antibiotics. Women with multiparous parity were more likely to develop puerperal sepsis than primiparous parity.

Keywords: Puerperal sepsis, Gram-positive bacteria, Gram-negative bacteria, Antimicrobial susceptibility, Felege Hiwot referral hospital, Women, Ethiopia

\section{Background}

Puerperal sepsis is any bacterial infection of the genital tract that occurs after child birth usually in the first $24 \mathrm{~h}$ [1] or at any time between the rupture of membranes or labor and the 42nd days of postpartum [2]. Following vaginal delivery, approximately $6-7 \%$ of women experience puerperal sepsis. Home birth in unhygienic conditions, poor nutrition, prim parity, anemia, prolonged rupture of membranes (PROM), prolonged labor, multiple vaginal examinations, caesarean section, instrumental deliveries, and postpartum hemorrhage are some of the risk factors for puerperal sepsis [3].

World Health Organization (WHO) estimated that about 350,000 maternal deaths occur during labor and childbirth of which $15 \%$ were associated with puerperal sepsis [4]. Puerperal sepsis causes at least 75,000 maternal deaths every year and mostly occurs in low-income countries with a distribution of $11.6 \%$ in Asia, $9.7 \%$ in Africa, $7.7 \%$ in Latin America and the Caribbean compared to the $2.1 \%$ in developed countries $[5,6]$. In Nigeria, puerperal sepsis accounted for $12 \%$ of maternal deaths [7] In Ethiopia, puerperal sepsis accounted for about $13 \%$ of all maternal deaths and became one of the top four causes of mortality [8].

Antibiotics are among the successful interventions developed to treat bacterial diseases including puerperal sepsis, but bacteria could develop resistance [9]. Resistance to antimicrobial agents has emerged as a public health problem at an alarming rate. Infecting agents capable of developing resistance to multiple drugs (MDR) have enhanced rate of morbidity and mortality [10]. The dynamic nature of bacteria resistant to antimicrobial agents can lead to prolonged illness, increased health care expenditures and risk of death.

Ethiopia has adopted the sustainable development goals (SDGs) to reduce maternal mortality to $<70 / 100,000$ by the year 2030. To achieve this target and significantly reduce maternal mortality, identifying the causes and contributors of puerperal sepsis is paramount. Therefore, this study was aimed to determine the proportion of bacterial isolates, their antimicrobial susceptibility profile and factors associated with puerperal sepsis among post-partum/ aborted women suspected for puerperal sepsis at Felege Hiwot Referal Hospital, Northwest Ethiopia.

\section{Methods}

Study design, area, and period

A cross sectional study was conducted from January to May 2017 among postpartum/aborted women admitted to Felege Hiwot Referral Hospital for medical services and suspected of puerperal sepsis.. The Hospital is found in Bahir Dar; the capital city of the Amhara Regional State. In the city, there were 14 healthcare serviceinstitutions (one government referral hospital, one primary hospital, two general private hospitals and ten health centers) during data collection.

\section{Study populations}

Postpartum/aborted women (any type of abortion) admitted to Felege Hiwot Referral Hospital during the study period. Women were suspected for puerperal sepsis if they develop fever of $>38.5^{\circ} \mathrm{C}$, pelvic pain, abnormal genital discharge with offensive smell and delay in the reduction of the size of uterus to the 42nd day of postpartum/abortion.

\section{Inclusion and exclusion criteria}

Women with sign and symptoms of puerperal sepsis at the time of admission or who developed sepsis during their stay in the hospital during the study period were included in the study. However, women with puerperal sepsis but started antibiotic therapy and those unable to give the interview were excluded.

\section{Sample size and sampling technique}

The sample size was determined using a single population proportion formula: $\mathrm{n}=\mathrm{z}^{2} \mathrm{p}(1-\mathrm{p}) / \mathrm{d}^{2}$; where: $\mathrm{n}=$ the number of postpartum/aborted women; $\mathrm{z}=$ standard normal distribution value at $95 \%$ CI $(\mathrm{z}=1.96) ; \mathrm{p}=$ the prevalence of puerperal sepsis. Taking $\mathrm{p}$ at $8.4 \%$ from study conducted in Addis Ababa, Ethiopia [11]; $\mathrm{d}=$ the margin of error, taken as 5\%. Accordingly, the sample size was $\left(\mathrm{n}=\frac{(\mathbf{1 . 9 6})^{2} \mathbf{0 . 0 8 4}(\mathbf{1 - 0 . 0 8 4})}{\mathbf{0 . 0 5}^{2}}\right)$ estimated at 119. Additional 47 women who fulfilled the inclusion and exclusion criteria were admitted to the hospital during the study period and included in the study. Hence, the final total sample size was 166. Convenient sampling was used to select the study participants. 


\section{Data collection}

\section{Socio-demographic and clinical data}

Socio-demographic characteristics of the study participants was collected using a pretested and structured questionnaire by $\mathrm{BSc}$ nursing graduates. The questionnaire was prepared in English and translated to the local Amharic language. The questionnaire was pretested on a sample of $5 \%$ of study participants at University of Gondar specialized Hospital and amended accordingly. The questionnaire was prepared based on the WHO education material on puerperal sepsis and customized to this study [1]. The clinical data of each woman was retrieved from their medical records.

\section{Nutritional status assessment}

The nutritional status of each woman was measured by mid upper arm circumference (MUAC using tape meter. MUAC less than $23 \mathrm{~cm}$ were considered as under nutrition [12].

\section{Assessment of anemia}

Postpartum/aborted women were screened for anemia using automated hematology analyzer (Cell-DYN 1800, Abbott diagnostic, USA). Each blood sample was investigated for total hemoglobin ( $\mathrm{Hgb})$ concentration. The Hgb thresholds were used to classify anemia. Anemia was categorized as mild (Hgb level 10 to $10.9 \mathrm{~g} / \mathrm{dl}$ ), moderate (Hgb level 7.0 to $9.9 \mathrm{~g} / \mathrm{dl}$ ) and severe (Hgb level < $7.0 \mathrm{~g} / \mathrm{dl})$ per WHO criteria [13].

\section{HIV screening}

The HIV status of each woman was collected from the medical record of each patient. Screening for HIV in the hospital was done with the First Response (Premier Medical Corporation, India), Unigold (Trinity Biotech Manufacturing, Ireland) and Vikia (bioMerieux SA, France) test algorithm.

\section{Blood collection and processing}

Blood was collected from each woman to detect the presence and frequency of bacteria.. Two bottles of blood ( $5 \mathrm{ml}$ for each bottle) was collected aseptically from two different sites of peripheral veins. Blood was inoculated directly into Trypton soya broth (Oxoid Ltd. Basingstoke, Hampshire, UK) and incubated aerobically at $37^{\circ} \mathrm{C}$. The growth of visible colonies were observed daily for the first 3 days. Subcultures were made on blood agar, Chocolate agar, and MacConkey agar (Oxoid Ltd. Basingstoke, Hampshire, UK) and examined for growth after $24-48 \mathrm{~h}$ of incubation. The procedure was repeated and negative blood cultures were reported after the 7 th day of incubation. Blood cultures positive for bacterial growth were further analyzed for colony isolation. Bacterial isolates were identified by gram stain and VITEK 2 identification and susceptibility testing system
(bioMerieux, Inc., Hazelwood, USA). Standard biochemical tests were also used as backup identification modalities [14].

\section{Antimicrobial susceptibility testing}

Antimicrobial susceptibility tests were done for each identified bacteria using the VITEK 2 identification and susceptibility testing system. The VITEK 2is an automated, walkway system that works on the principle of photometry. Briefly, pure colony of the isolated bacteria was emulsified in $2 \mathrm{ml}$ of $0.85 \%$ normal saline. Bacterial suspensions with an optical density of $0.5-0.63$ was taken as acceptable bacterial concentration. Reagents were then immersed to the suspension and transferred to VITEK 2 system for antimicrobial susceptibility testing [15].

\section{Quality control}

Training for data collectors and supervisors about the study and data collection procedures was given. Consistency and completeness of data was also checked on daily bases. The working standards of materials, equipment, culture media and procedures were strictly followed. The sterility of culture media was ensured by incubating $5 \%$ of each batch at $37^{\circ} \mathrm{C}$ for $24 \mathrm{~h}$. The performance of each media was checked by inoculating standard strains of E. coli (ATCC 25922) for Gramnegative bacteria, S. aureus (ATCC 25923) for Grampositive bacteria and N. gonorrhoeae (ATCC49226) for fastidious bacteria [16]. The VITEK 2 system was also verified using known strains.

\section{Data processing and analysis}

Socio-demographic and laboratory data were entered and analyzed using SPSS version 20. Descriptive statistics was presented as frequencies and percentages in tables and figures. Logistic regressions were used to assess factors associated with puerperal sepsis. Odds ratio with its 95\% CIs was used to assess the presence of association and its significances was declared at $P$-values < 0.05 .

\section{Results \\ Socio-demographic and clinical characteristics}

During the study period, a total of 756 women were admitted for postpartum/abortion medical services. Of these, 166 women suspected for puerperal sepsis and enrolled in the study. The mean age of the study participants was 27.3 years $(\mathrm{SD} \pm 6.2)$. Data on educational status showed that $42.2 \%$ were unable to read and write, $36.7 \%$ had secondary school and above while $21.1 \%$ attended only elementary school. Majority (134, 80.7\%) of cases of puerperal sepsis was related with labor while $32(19.3 \%)$ was related with abortion. Of the laboring 
mothers, 91 (67.9\%) gave birth through caesarean section (CS) and 43 (32.1\%) through spontaneous vaginal delivery (SVD). Half $(83,50 \%)$ of the study participants were living in rural areas and the remaining were urban residents (Table 1). Twenty (12\%) of women did not follow antenatal care. Among the 134 laboring mothers, eleven women $(6.6 \%)$ were found to be HIV positive.

\section{Proportion of bacterial isolates}

The overall prevalence of bacterial isolates among women suspected of puerperal sepsis was 33.7\% (56/ 166). The proportion of Gram-negative bacteria was $58.9 \%$ (33/56) and that of Gram-positive was $41.1 \%$ (23/ 56). Overall, S. aureus was the dominant isolate (33.9\%; 19/56) followed by E. coli (32.1\%; 18/56) (Fig. 1). The proportion of Gram-negative isolates was $54.5 \%(18 / 33)$ for E. coli, $21.2 \%$ (7/33) for K. pneumonaie $18.2 \%(6 / 33)$ for A. baumannii and that of Raoultella orinthinolytica was $3.6 \%(2 / 33)$. On the other hand, the proportion of Gram-positive isolates was $82.6 \%$ (19/23) for S. aureus and $17.4 \%($; 4/23) for CoNS.

\section{Antimicrobial susceptibility profiles of gram-positive bacteria}

Gram-positive bacteria demonstrated high rate of resistance to Tetracycline (100\%), Erythromycin (87\%) and Penicillin (61\%). However, gram positive bacteria showed low rate of resistance to Ciprofloxacin (4.3\%), Vancomycin (13\%) and Ceftriaxone (13\%). S. aureus isolates were susceptible to Vancomycin (100\%) but resistant to
Cefoxitin (47.4\%), Erythromycin (84.2\%) and Tetracycline (100\%). The drug susceptibility profile of CoNS isolates showed resistance to Penicillin (100\%), Ampicillin (100\%), Tetracycline (100\%) and Erythromycin (100\%). None of the Gram-positive bacteria were susceptible for all antimicrobials tested (Table 2).

\section{Antimicrobial susceptibility profiles of gram-negative bacteria}

Gram-negative bacteria showed high rate of sensitivity to Gentamicin (78.8\%) and Ciprofloxacin (75.8\%) while high rate of resistance was observed for Cefazolin (72.7\%), Tetracycline (93.9\%) and Ampicillin (100\%). Species specific resistance of Gram-negative bacteria showed that $E$. coli were resistant to Ampicillin (100\%) and Tetracycline (100\%). Nevertheless, all isolates of $E$.coli were susceptible to Ciprofloxacin and Gentamicin. K. pneumoniae isolates were highly resistant to Ampicillin (100\%) andTetracycline (100\%). However; relatively sensitive isolates were observed for Trimethoprim/Sulfamethoxazole (57.1\%), Ceftriaxone (57.1\%) and Gentamicin (57.1\%). A. boumanni isolates were resistant to trimethoprim/Sulfamethoxazole (100\%) and Ampicillin (100\%). Isolates of Raoultella orinthinolytica were resistant for most antibiotics tested except to Tetracycline (Table 3).

\section{The proportion of multidrug resistant (MDR) bacterial isolates}

Among the 56 isolates tested for susceptibility, 84\% showed resistance to 3 or more classes of antibiotics.

Table 1 Socio demographic characteristics of women suspected of puerperal sepsis at Felege Hiwot Referral Hospital, Bahir Dar, Northwest Ethiopia, 2017, $(n=166)$

\begin{tabular}{|c|c|c|c|c|}
\hline \multirow[t]{2}{*}{ Variable } & & \multirow{2}{*}{$\begin{array}{l}\text { Frequency } \\
\mathrm{N},(\%)\end{array}$} & \multicolumn{2}{|c|}{ Bacterial isolates } \\
\hline & & & Yes, $N(\%)$ & No, $N(\%)$ \\
\hline \multirow[t]{3}{*}{ Age } & $18-24$ & $68(41)$ & $22(32.4)$ & $46(67.6)$ \\
\hline & $25-34$ & 69 (41.6) & $17(24.6)$ & $52(75.4)$ \\
\hline & $35-42$ & $29(17.5)$ & $17(58.6)$ & $12(41.4)$ \\
\hline \multirow[t]{4}{*}{ Educational Status } & Illiterate & $70(42.2)$ & $29(41.4)$ & $41(58.6)$ \\
\hline & $1-4$ grade & $14(8.4)$ & $8(57.1)$ & $6(42.9)$ \\
\hline & 5-8 Grade & $21(12.7)$ & $6(28.6)$ & $15(71.4)$ \\
\hline & Secondary and Above & $61(36.7)$ & $13(21.3)$ & $38(78.7)$ \\
\hline \multirow[t]{5}{*}{ Occupation } & Government Employee & $36(27.7)$ & $7(19.4)$ & 29 (80.6) \\
\hline & Farmer & $65(39.2)$ & $26(40)$ & $39(60)$ \\
\hline & Merchant & $17(10.2)$ & $8(47)$ & $9(53)$ \\
\hline & House Wife & $37(22.2)$ & $13(35.1)$ & $24(64.9)$ \\
\hline & Other & $11(6.7)$ & $2(18.2)$ & $9(81.8)$ \\
\hline \multirow[t]{2}{*}{ Residence } & Rural & $86(51.8)$ & $26(30.2)$ & $60(69.8)$ \\
\hline & Urban & $80(48.2)$ & $30(37.5)$ & $50(62.5)$ \\
\hline \multirow[t]{2}{*}{ Religion } & Orthodox & $148(89.2)$ & $48(32.4)$ & $100(67.6)$ \\
\hline & Muslim & $18(10.8$ & $8(44.4)$ & $10(55.6)$ \\
\hline
\end{tabular}






Fig. 1 Frequency (\%) of bacterial isolates from women suspected of puerperal sepsis at Felege Hiwot Referral hospital, Bahir Dar, Northwest Ethiopia, 2017

The proportion of bacteria resistant to 3 different antimicrobials was $21.4 \%$ while $55.4 \%$ were resistant to more than three classes of antibiotics. The proportion of MDR S. aureus was $52.6 \%(10 / 19)$. The study also showed high rate of MDR CoNS (Table 4).

The antimicrobial susceptibility profile of Gramnegative isolates showed significant rate of MDR. The proportion of MDR E. coli was $44.4 \%$ and that of K. pnemonaie was $42.9 \%$. In addition, $66.7 \%$ of $A$. baumanii and all $R$. ornithinolytica isolates were MDR (Fig. 2).

\section{Factors associated with puerperal sepsis}

In this study; parity, HIV status, antenatal care, duration of labour, membrane rupture, mode of delivery, diabetes mellitus, method of placenta removal, hypertension, anemia and place of delivery were evaluated as possible factors associated with puerperal sepsis. In the binary analysis; multiparous parity, antenatal care, diabetes mellitus and anemia showed $\mathrm{s}$ association with puerperal sepsis $(P<0.05)$. The multivariable regression analysis showed that only being multiparous parity had statistically significant association with puerperal sepsis. Women that had multiparous parity were four times more likely to develop puerperal sepsis compared to primiparous women $(\mathrm{AOR}=4.045 ; 95 \%$ CI: 1.479 $11.061 ; P=0.006)$. Other socio-demographic and clinical variables had no significant association with puerperal sepsis (Table 5).

\section{Discussion}

Puerperal sepsis is one of the leading causes of preventable maternal morbidity and mortality [17]. In the present study, about one third of women suspected of puerperal sepsis were infected with one or more bacterial isolates with an overall proportion of $33.7 \%$. Previous study from Ethiopia reported similar findings (33.3\%) [18]. On the other hand, the proportion of bacterial isolates causing puerperal sepsis was lower than reports

Table 2 Antimicrobial susceptibility profile of Gram-positive bacteria isolated from women suspected of puerperal sepsis at Felege Hiwot Referral Hospital, Bahir Dar, Northwest Ethiopia, 2017

\begin{tabular}{|c|c|c|c|c|c|c|c|c|c|c|c|}
\hline \multirow{2}{*}{$\begin{array}{l}\text { Bacterial } \\
\text { Isolates }\end{array}$} & \multicolumn{11}{|c|}{ Resistance Rate, N (\%) } \\
\hline & $P$ & AMP & VAN & CXT & SXT & CIP & CRO & TE & CAF & $E$ & $\mathrm{DA}$ \\
\hline S.aureus $(n=19)$ & $10(52.6)$ & $8(42.1)$ & 0 & $9(47.4)$ & $6(31.6)$ & $2(10.5)$ & $2(10.5)$ & $19(100)$ & $7(36.8)$ & $16(84.2)$ & $5(26.3)$ \\
\hline CoNs $(n=4)$ & $4(100)$ & $4(100)$ & $3(75)$ & $3(75)$ & $2(50)$ & $1(25)$ & $2(50)$ & $4(100)$ & $1(25)$ & $4(100)$ & $3(75)$ \\
\hline Total $(n=23)$ & $14(61)$ & $12(52)$ & $3(13)$ & $12(52)$ & $8(35)$ & $3(13)$ & $4(17)$ & $23(100)$ & $8(35)$ & $20(87)$ & $8(35)$ \\
\hline
\end{tabular}

CoNS Coagulase negative Staphylococcus, DA Clindamycin, CXT Cefoxitin, E Erythromycin, $P$ Penicillin, SXT Trimethoprim-sulfamethoxazole, TE Tetracycline, AMP Ampicillin, CRO Ceftriaxone, CAF Chloramphenicol, CIP Ciprofloxacin 
Table 3 Antimicrobial susceptibility profile of Gram-negative bacteria isolated from women suspected of puerperal sepsis at Felege Hiwot Referral Hospital, Bahir Dar town, Northwest Ethiopia, 2017

\begin{tabular}{|c|c|c|c|c|c|c|c|c|c|c|}
\hline \multirow[t]{2}{*}{ Bacterial isolates } & \multicolumn{10}{|c|}{ Resistance rate, $N(\%)$} \\
\hline & SXT & AMC & $\mathrm{TE}$ & CIP & GEN & CRO & CZN & AMP & CAZ & CAF \\
\hline E.coli $(n=18)$ & $6(33.3)$ & $7(38.8)$ & $18(100)$ & 0 & 0 & $7(38.8)$ & $10(55.5)$ & $18(100)$ & $6(33.3)$ & $2(11.1)$ \\
\hline K.pneumoniae $(n=7)$ & $3(42.8)$ & $4(57.1)$ & $7(100)$ & $4(57.1)$ & $3(42.8)$ & $4(57.1)$ & $7(100)$ & $7(100)$ & $4(57.1)$ & $3(42.8)$ \\
\hline A.baumannii $(n=6)$ & $6(100)$ & $5(83.3)$ & $6(100)$ & $2(33.3)$ & $2(33.3)$ & $3(50)$ & $5(83.3)$ & $6(100)$ & $3(50)$ & $2(33.3)$ \\
\hline R.orinthinolytica $(n=2)$ & $1(50)$ & $2(100)$ & 0 & $2(100)$ & $2(100)$ & $2(100)$ & $2(100)$ & $2(100)$ & $2(100)$ & $2(100)$ \\
\hline Total = 33 & $16(48.5)$ & $18(54.5)$ & $31(93.9)$ & $8(24.2)$ & $7(21.2)$ & $16(48.5))$ & $24(72.7)$ & $33(100)$ & $15(45.5)$ & $9(27.2)$ \\
\hline
\end{tabular}

SXT Trimethoprim-Sulfamethoxazole, AMC Amoxicillin-clavulanate, TE Tetracycline, Amp Ampicillin, CIP Ciprofloxacin, GEN Gentamicin, CRO Ceftriaxone, CAZ Ceftazidam and CAF Chloramphenicol

from Nigeria (82.7\%), Sudan (72.9\%), and Bangladesh $(84 \%)[16,19,20]$. These discrepancies might be attributable to cultural, health seeking behavior, health care coverage, period of studies conducted and other socioeconomic factors.

In this study, the proportion of bacterial isolates causing puerperal sepsis was higher than reports from Nepal (19.7\%) and Uganda (17\%) [21, 22]. This difference can be explained by fact that two-third (67.9\%) of women gave birth through caesarean section (CS). Postnatal infections (pyrexia, endometritis, and puerperal sepsis), thrombosis and excessive blood loss are indeed higher after caesarean section [23].

The prevalence of Gram-positive bacteria causing puerperal sepsis was $41.1 \%$ and $S$. aureus was the dominant isolate (33.9\%). This is consistent with previous study that report $S$. aureus as one of the major bacteria isolated from puerperal septic patients [16, 19]. S. aureus is frequently found on the skin and can be easily acquired during delivery [24].

The prevalence of Gram-negative bacteria was $58.9 \%$ and $E$ coli was the dominant isolate (32.1\%). This finding is higher than reports isolated from women with puerperal sepsis in Bangladesh (14.5\%) [20] and Nigeria (15.8\%) [25]. It is known that $E$. coli are among the commonest bacterial isolates causing blood stream infections, wounds and other complications in humans [26, 27]. K. pnemonaie with a prevalence of $(12.5 \%)$ was found to be the third frequently isolated bacteria among women with puerperal sepsis in our study. It is recently emerged as a significant cause of hospital acquired infections (urinary tract infection, pneumonia and septicemia) especially among immune compromised individuals $[28,29]$ which can be sources of infection for puerperal sepsis.

Two very uncommon bacterial pathogens namely $A$. baumannii and $R$. orinthinolytica were isolated from the blood culture of women suspected of puerperal sepsis. $A$. baumannii is an opportunistic bacteria affecting people with compromised immune systems and increasingly important hospital acquired infection [30]. It has been noted for its apparent ability to survive on artificial surfaces for extended period of time that can allow it to persist in the hospital environment as a source of puerperal sepsis [31].

This study revealed that $E$. coli isolates were susceptible to Ciprofloxacin (100\%) and Gentamicin (100\%). Similar susceptibility profiles were reported form Ethiopia around Jimma and Gondar [32, 33]. On the other hand, resistance to Ampicillin (100\%) was observed among E. coli isolates consistent with reports from India and Ethiopia [20,32]. This is because; E. coli has resistant genes for beta-lactam agents including ampicillin [34-36] and has selective pressure excreted by overuse of the antibiotics.

Table 4 Multi-drug resistance profile of bacterial isolates from women suspected of puerperal sepsis at Felege Hiwot Referral Hospital, Northwest Ethiopia, 2017

\begin{tabular}{|c|c|c|c|c|c|c|c|c|c|}
\hline \multirow[t]{2}{*}{ Bacterial pathogens } & \multicolumn{8}{|c|}{ Patterns of drug resistance } & \multirow{2}{*}{$\begin{array}{l}\text { Total } \\
\text { MDR } \\
(\%)\end{array}$} \\
\hline & RO (\%) & R1 (\%) & R2 (\%) & R3 (\%) & R4 (\%) & R5 (\%) & R6 (\%) & R7 (\%) & \\
\hline S. aureus $(n=19)$ & 0 & $3(15.8)$ & $6(31.6)$ & $1(5.3)$ & $1(5.3)$ & $1(5.3)$ & $1(5.3)$ & $6(31.6)$ & $10(52.6)$ \\
\hline CoNS $(n=4)$ & 0 & 0 & 0 & 0 & $1(25)$ & 0 & 0 & $3(75)$ & $4(100)$ \\
\hline E. coli $(n=18)$ & 0 & 0 & 0 & $8(44.4)$ & $3(16.6)$ & 0 & $1(5.5)$ & $6(33.4)$ & $18(100)$ \\
\hline K.pnuemonaie $(n=7)$ & 0 & 0 & 0 & $3(42.9)$ & 0 & 0 & 0 & $4(57.1)$ & $7(100)$ \\
\hline A.baumannii $(n=6)$ & 0 & 0 & 0 & 0 & $1(16.6)$ & $1(16.6)$ & 0 & $4(66.7)$ & $6(100)$ \\
\hline R.orinthinolytica $(n=2)$ & 0 & 0 & 0 & 0 & 0 & 0 & 0 & $2(100)$ & $2(100)$ \\
\hline Total $(n=56)$ & 0 & $3(5.4)$ & $6(10.7)$ & $12(21.4)$ & $5(8.9)$ & $2(3.6)$ & $2(3.6)$ & $22(39.3)$ & $47(84)$ \\
\hline
\end{tabular}

Key: $R_{0}$ : susceptible to all antimicrobials; $R 1-7$ : resistance to 1, 2, 3, 4, 5, 6 \& 7 antimicrobials 




Bacterial isolates

Fig. 2 The proportion of multidrug resistant bacterial isolates from women suspected of puerperal sepsis at Felege Hiwot Referral Hospital, Bahir Dar, Northwest Ethiopia, 2017

Table 5 Bivariate and multivariable analysis of factors associated with of puerperal sepsis at Felege Hiwot Referral Hospital, Bahir Dar, Northwest Ethiopia, 2017

\begin{tabular}{|c|c|c|c|c|c|c|c|}
\hline \multirow[t]{2}{*}{ Variable } & & \multicolumn{2}{|c|}{ Bacterial isolate } & \multirow[b]{2}{*}{$\operatorname{COR}(95 \% \mathrm{Cl})$} & \multirow[b]{2}{*}{$P$-Value } & \multirow[b]{2}{*}{ AOR $(95 \% \mathrm{Cl})$} & \multirow[b]{2}{*}{$P$-value } \\
\hline & & $\overline{\mathrm{No}}$ & Yes & & & & \\
\hline \multirow[t]{2}{*}{ Parity } & Primiparous & 60 & 20 & 1 & $0.023^{a}$ & 1 & $0.006^{\mathrm{a}}$ \\
\hline & Multiparous & 50 & 36 & 2.160 (1.113-4.192) & & $4.045(1.479-11.061)$ & \\
\hline \multirow[t]{2}{*}{ HIV } & No & 104 & 51 & 1 & 0.399 & & \\
\hline & Yes & 6 & 5 & $1.699(0.495-5.833)$ & & & \\
\hline \multirow[t]{2}{*}{ ANC } & Booked & 92 & 54 & 1 & $0.030^{\mathrm{a}}$ & 1 & \\
\hline & Un booked & 18 & 2 & $0.189(0.042-0,848)$ & & 0.000 & \\
\hline \multirow[t]{2}{*}{ Duration of labor } & $<18 \mathrm{~h}$ & 59 & 29 & 1 & 0.094 & 1 & 0.101 \\
\hline & $>=18 \mathrm{~h}$ & 24 & 22 & 1.865 (0.899-3.868) & & $2.058(0.868-4.879)$ & \\
\hline \multirow[t]{2}{*}{ Membrane rupture } & $0-8 \mathrm{~h}$ & 59 & 29 & 1 & 0.094 & 1 & 0.761 \\
\hline & $>8 \mathrm{~h}$ & 24 & 22 & $1.865(0.899-3.868)$ & & $1.151(0.464-2.859)$ & \\
\hline \multirow[t]{2}{*}{ Mode of delivery } & Vaginal & 28 & 15 & 1 & 0.603 & & \\
\hline & CS & 55 & 36 & $1.220(0.574-2.599)$ & & & \\
\hline \multirow[t]{3}{*}{ Placenta removal } & Spontaneous & 19 & 3 & 1 & 0.703 & & \\
\hline & Cord Traction & 8 & 0 & 0.000 & & & \\
\hline & Manual & 1 & 2 & $2.923(0.239-35.68)$ & & & \\
\hline \multirow[t]{2}{*}{ Diabetes mellitus } & No & 107 & 49 & 1 & & 1 & 0.117 \\
\hline & Yes & 3 & 7 & $5.095(1.264-20.54)$ & $0.022^{\mathrm{a}}$ & $3.471(0.733-16.433)$ & \\
\hline \multirow[t]{2}{*}{ Hypertension } & No & 104 & 55 & 1 & 0.291 & & \\
\hline & Yes & 6 & 1 & $0.315(0.037-2.684)$ & & & \\
\hline \multirow[t]{4}{*}{ Anemia } & None & 50 & 33 & 1 & $0.040^{a}$ & 1 & 0.36 \\
\hline & Mild & 23 & 4 & $0.264(0.084-0.832)$ & & $0.111(0.020-0.608)$ & \\
\hline & Moderate & 20 & 15 & $1.136(0.510-2.531)$ & & $0.846(0.287-2.494)$ & \\
\hline & Sever & 17 & 4 & $0.357(0.110-1.154)$ & & $0.229(0.045-1.155)$ & \\
\hline \multirow[t]{2}{*}{ Place of delivery } & Heath institute & 81 & 47 & 1 & & 1 & 0.729 \\
\hline & Home & 29 & 9 & $0.535(0.233-1.226)$ & 0.139 & $0.816(0.179-3.707)$ & \\
\hline
\end{tabular}


Multiple drug resistance (MDR) is an emerging public health threat that has been reported in different countries [37]. In our study, the overall proportion of MDR isolates was $84 \%$. Similar finding were reported from Uganda $(80 \%)$ that majority of puerperal sepsis were caused by MDR bacteria [22]. S. aureus were highly resistant to Tetracycline (consistent with other studies) [30] and unusually to Erythromycin. Similarly, $47.4 \%$ of $S$. aureus isolates showed resistance to Cefoxtin which is relatively lower than reports from India $(53.2 \%)[38,39]$. More than half $(52.6 \%)$ of $S$. aureus isolates were resistant to three or more tested antimicrobials (MDR) This can be explained by its unique features to adapt antimicrobial pressures and genetic competence to acquire antibiotic resistant genes from other strains.

Relatively high proportion of MDR was observed among E .coli, A. baumannii, and K. pneumonaie isolates. K. pneumonaie has chromosomal and plasmid encoded betalactam hydrolyzing enzymes [40]. A. baumannii is clinically important pathogen and causes septicemia with widespread resistance to various antibiotics [41]. There are reports that showed resistance of $R$. ornithinolytica to ampicillin and other commonly used antibiotics which can be associated with the presence of $\beta$-lactamases [42, 43].

Puerperal sepsis can be associated with different sociodemographic and clinical factors. In the present study, statistically significant association was observed between multiparous parity and puerperal sepsis. Women that had multiparous parity were four times more likely to develop puerperal sepsis compared to primiparous women $(\mathrm{AOR}=$ 4.045; 95\% CI: 1.479-11.061; $P=0.006$ ). Similar finding was reported from Pakistan that high prevalence of puerperal sepsis was observed among women of multiparous parity (78.29\%) [44].

Although it is not significantly associated, women with age greater than 34 years had high proportion of culture positive bacterial infection (58.6\%). This is supported by previous study from Pakistan indicating that majority (65.11\%) of women admitted with puerperal sepsis were above 30 years of age [44]. Previous study reported that rural residence, educational level, family monthly income, prolonged labour $(>24 \mathrm{~h})$, delivery by caesarean section, ANC follow up, ruptured membrane ( $>24 \mathrm{~h}$ before delivery), frequent vaginal examination and being referred were reported as significant factors associated with puerperal sepsis [45]. But in our study HIV status, antenatal care, duration of labour, membrane rupture, mode of delivery, diabetes mellitus, method of placenta removal, hypertension, anemia and place of delivery had significant association with puerperal sepsis.

\section{Limitation of the study}

The limitation of the study include: investigation for anaerobic bacteria that can cause significant puerperal sepsis was not done. The study was conducted only in a public referral hospital that lacks representativeness and difficult to generate generalized conclusions. Convenient sampling was used to select study participants that can allow missing of cases. In addition, the nutritional status of post-partum/aborted women was measured by MUAC that may not be enough to determine nutritional status as a single measurement.

\section{Conclusion}

About one third of post-partum/aborted women suspected for puerperal sepsis were infected with one or more bacterial isolates. E. coli and S. aureus were the most dominant bacteria isolated from post-partum/aborted women. Significant proportion of bacterial isolates showed mono and multi-drug resistance rates. Relatively high rate of resistance was observed to Tetracycline and Ampicillin. The very uncommon bacterial isolates of $A$. baumanni and $R$. ornithinolytica showed high rate of resistance to the commonly prescribed antibiotics. Post-partum/aborted women with multiparous parity were more likely to develop puerperal sepsis than primiparous parity. Systematic surveillance for the commonly prescribed antibiotics and uncommon bacterial isolates is recommended to maintain the emergence and spread of antimicrobial resistance. In addition; awareness about post-partum/abortion complications and available cares are needed.

\section{Abbreviations \\ AIDS: Acquired Immune Deficiency Syndrome; ATCC: American Type Cell Culture; CLSI: Clinical Laboratory Standard Institute; CoNS: Coagulase Negative Staphylococcus; CS: Cesarean Section; DM: Diabetic Mellitus; HIV: Human Immune Deficiency Virus; MDR: Multi Drug Resistance; MUAC: Mid Upper Arm Circumference; PROM: Prolonged rupture of membranes; SDGs: Sustainable Developmental Goals; SVD: Spontaneous vaginal delivery; TMP/SMX: Trimethoprim/Sulphametaxone; VRE: Vancomycin Resistance Enterococci; WHO: World Health Organization}

\section{Acknowledgements}

We would like to thank the Department of Medical Microbiology, College of Medicine and Health Sciences, University of Gondar for their support for this study. We also thank staffs of Felege Hiwot Referral Hospital laboratory and maternity ward in general for all the support during data collection and processing of samples. All women involved in this study are also acknowledged.

\section{Authors' contributions}

AA: Designed the study, collected and analyzed the data and participated in the draft and final write up of the manuscript; BG: Participated in conception and design of the study, data analysis and interpretations and preparation of the draft and final write up of the manuscript; BT: participated in proposal writing, data analysis and interpretation of results; AW: involved in data collection, clinical diagnosis and characterization of patients; AM: interpret results and prepared the manuscript. All authors read and approved the manuscript.

\section{Funding}

Not applicable; no funding was received for this study.

\section{Availability of data and materials}

Data were collected from puerperal sepsis suspected women admitted to Felege Hiwot Referral Hospital, Bahir Dar, Northwest Ethiopia. The datasets are available from the corresponding author upon reasonable request 
through alemalea@gmail.com but will not be shared publicly to ensure patient confidentiality.

\section{Ethics approval and consent to participate}

Ethical clearance was obtained from the Ethical Review Committee of School of Biomedical and Laboratory Sciences, College of Medicine and Health Sciences, University of Gondar with Ref. No SBMLS/62/5/09 Letter of cooperation was given to Felege Hiwot Referral Hospital prior to data collection. After explaining the purpose and objective of the study, informed consent was obtained from each woman. Any woman who was not willing to participate in the study was not forced to participate. All data obtained were kept confidential by using codes and no personal identifiers were used. Blood samples collected were used only for the purpose of the study. The laboratory results were communicated to their attending physicians for appropriate intervention.

\section{Consent for publication}

Not applicable

\section{Competing interests}

The authors declare that they have no competing interests.

\section{Author details}

${ }^{1}$ Department of Medical Laboratory Science, College of Medicine and Health Sciences, Bahir Dar University, Bahir Dar, Ethiopia. ${ }^{2}$ Department of Medical Microbiology, School of Biomedical and Laboratory Science, College of Medicine and Health Sciences, University of Gondar, Gondar, Ethiopia. ${ }^{3}$ Department of Gynecology and Obstetrics, School of Medicine, Bahir Dar University, Bahir Dar, Ethiopia.

\section{Received: 8 August 2019 Accepted: 29 December 2019}

\section{Published online: 13 January 2020}

\section{References}

1. World Health Organization. Education material for teachers of midwifery: midwifery education modules. 2nd ed; 2008.

2. World Health Organization (WHO). The prevention and management of puerperal infections : report of a technical working group. Geneva: World Health Organization; 1992. https://apps.who.int/iris/handle/10665/59429.

3. Maharaj D. Puerperal pyrexia: a review. Part I. Obstet Gynecol Surv. 2007;62(6):393-9.

4. Buddeberg BS, Aveling W. Puerperal sepsis in the 21st century: progress, new challenges and the situation worldwide. Postgrad Med J. 2015; 91(1080):572-8.

5. Van Dillen J, Zwart J, Schutte J, van Roosmalen J. Maternal sepsis: epidemiology, etiology and outcome. Curr Opin Infect Dis. 2010;23(3):249-54

6. Kehoe S, Neilson J, Norman J. Maternal and infant deaths: chasing millennium development goals 4 and 5. London: RCOG; 2010. p. 433.

7. Dare F, Bako A, Ezechi O. Puerperal sepsis: a preventable post-partum complication. Trop Dr. 1998;28(2):92-5.

8. Berhan Y, Berhan A. Causes of maternal mortality in Ethiopia: a significant decline in abortion related death. Ethiop J Health Sci. 2014;24:15-28.

9. Martinez JL. General principles of antibiotic resistance in bacteria. Drug Discov Today Technol. 2014;11:33-9.

10. Van der Tak J. Abortion, fertility, and changing legislation: an international review: Lexington books; 1974

11. Fikremelekot T. Incidence and determinants of puerperal fever among Parturients who gave birth in a tertiary teaching hospital. Addis Ababa: AAU; 2014.

12. Tang AM, Dong K, Deitchler M, Chung M, Maalouf-Manasseh Z, Tumilowicz A, et al. Use of cutoffs for mid-upper arm circumference (MUAC) as an indicator or predictor of nutritional and health-related outcomes in adolescents and adults: a systematic review. 2013.

13. World Health Organization (WHO). Haemoglobin concentrations for the diagnosis of anemia and assessment of severity. Vitamin and Mineral Nutrition Information System. Geneva: WHO; 2011.

14. Cheesbrough M. District laboratory practice in tropical countries-part 2. 2nd ed. New York: Cambridge University press; 2006. p. 442.

15. Romero-Gómez M-P, Gómez-Gil R, Paño-Pardo JR, Mingorance J. Identification and susceptibility testing of microorganism by direct inoculation from positive blood culture bottles by combining MALDI-TOF and Vitek-2 compact is rapid and effective. J Infect. 2012;65(6):513-20.
16. Ahmed Ml, Alsammani MA. Babiker RA. Puerperal Sepsis in a rural Hospital in Sudan. Mater Sociomed. 2013;25(1):19-22.

17. Maharaj D. Puerperal pyrexia: a review. Part II. Obstet Gynecol Surv. 2007; 62(6):400-6.

18. Duncan M, Perine P, Krause D, Awoke S, Zaidi A. Pelvic inflammatory disease and puerperal sepsis in Ethiopia: II. Treatment. Am J Obstet Gynecol. 1980; 138(7):1059-63.

19. Bako B, Audu BM, Lawan ZM, Umar JB. Risk factors and microbial isolates of puerperal sepsis at the University of Maiduguri Teaching Hospital, Maiduguri, North-Eastern Nigeria. Arch Gynecol Obstet. 2012; 285(4):913-7.

20. Tamboli SS, Tamboli SB, Shrikhande S. Puerperal sepsis: predominant organisms and their antibiotic sensitivity pattern. Int J Reprod Contracept Obstet Gynecol. 2017;5(3):762-5.

21. Pradhan B, Shrestha SD, Bhandary S, Singh A, Shrestha R. Puerperal Sepsis and its cause in Patan hospital. Nepal J Obstet Gynaecol. 2015;10(1):33-5.

22. Lisa M, Joseph N, Joel B, Yarine F, Adeline A, Mark J, et al. Antimicrobialresistant infections among postpartum women at a Ugandan referral hospital. PLoS One. 2017;12(4):e0175456. https://doi.org/10.1371/journal. pone.0175456

23. Zarko A, Stephen M, Stefania L. Caesarean section versus vaginal delivery for preterm birth in singletons. Cochrane Database Syst Rev. 2012. https://doi. org/10.1002/14651858.CD000078.pub2.

24. Naber CK. Staphylococcus aureus bacteremia: epidemiology, pathophysiology, and management strategies. Clin Infect Dis. 2009; 48(Supplement 4):S231-S7.

25. Bako B, Ibrahim UN, Umar JB, Zamo AB. Microbial Isolates in Puerperal Sepsis and their in vitro Antibiotic Sensitivity in North Eastern Nigeria. Women's Health Care. 2012;1(107):2167-0420.

26. Biedenbach DJ, Moet GJ, Jones RN. Occurrence and antimicrobial resistance pattern comparisons among bloodstream infection isolates from the SENTRY antimicrobial surveillance program (1997-2002). Diagn Microbiol Infect Dis. 2004;50(1):59-69.

27. Gebre-Sealsssie S. Antimicrobial resistance patterns of clinical bacterial isolates in southwestern Ethiopia. Ethiop Med J. 2007;45(4):363-70.

28. Zaidi AK, Thaver D, Ali SA, Khan TA. Pathogens associated with sepsis in newborns and young infants in developing countries. Pediatr Infect Dis J. 2009:28(1):S10-S8.

29. Ghotaslou R, Ghorashi Z, Nahaei M. Klebsiella pneumoniae in neonatal Sepsis: a 3-year-study in the pediatric hospital of Tabriz Iran. Jpn J Infect Dis. 2007;60(2/3):126

30. Biadglegne F, Abera B, Alem A, Anagaw B. Bacterial isolates from wound infection and their antimicrobial susceptibility pattern in Felege Hiwot referral Hospital North West Ethiopia. Ethiop J Health Sci. 2009;19(3):173-7.

31. Antunes LC, Visca P, Towner KJ. Acinetobacter baumannii: evolution of a global pathogen. Pathog Dis. 2014;71(3):292-301.

32. Beyene $\mathrm{G}$, Tsegaye $\mathrm{W}$. Bacterial uropathogens in urinary tract infection and antibiotic susceptibility pattern in Jimma University specialized hospital, Southwest Ethiopia. Ethiop J Health Sci. 2011;21(2):141-6.

33. Tiruneh M, Yifru S, Gizachew M, Molla K, Belyhun Y, Moges F, et al. Changing trends in prevalence and antibiotics resistance of uropathogens in patients attending the Gondar University hospital, Northwest Ethiopia. Int J Bacteriol. 2014:2014:629424

34. Shehab El-Din EMR, El-Sokkary MMA, Bassiouny MR, Hassan R. Epidemiology of Neonatal Sepsis and Implicated Pathogens: A Study from Egypt. Biomed Res Int. 2015;2015:509484.

35. Aamir MM, Ali AE, Hamouda HM, Mourad FE. Prevalence of multidrug resistant Bacteria causing late-onset neonatal Sepsis. Int J Curr Microbio App Sci. 2015:4(5):172-90.

36. Gebrehiwot A, Lakew W, Moges F, Anagaw B, Yismaw G, Unakal C. Bacterial profile and drug susceptibility pattern of neonatal sepsis in Gondar University hospital, Gondar Northwest Ethiopia. Der Pharmacia Lettre. 2012; 4(6):1811-6

37. Walsh AL, Phiri AJ, Graham SM, et al. Bacteremia in febrile Malawian children: clinical and microbiologic features. Pediatr Infect Dis J. 2000;19:312-8.

38. Ge T. Bacterial etiologic agents causing neonatal sepsis, their antimicrobia susceptibility pattern and associated risk factors at University of Gondar Hospital, North -West Ethiopia; 2016.

39. Singh L, Cariappa M, Das N. Drug sensitivity pattern of various Staphylococcus species isolated at a tertiary care hospital. Med J Armed Forces India. 2016;72:S62-S6. 
40. Thenmozhi S, Moorthy M, Sureshkumar B, Suresh M. Antibiotic resistance mechanism of ESBL producing Enterobacteriaceae in clinical field: a review. Int J Pure Appl Biosci. 2014;2:207-26.

41. Mindolli PB, Salmani MP, Vishwanath G, Manumanthappa A. Identification and speciation of Acinetobacter and their antimicrobial susceptibility testing. Al Ameen J Med Sci. 2010;3(4):345-9.

42. Hostacká A. Antibiotic susceptibility, serum response and surface properties of Klebsiella species. Microbios. 2000;104(408):115-24.

43. Walckenaer E, Poirel L, Leflon-Guibout V, Nordmann P, Nicolas-Chanoine MH. Genetic and biochemical characterization of the chromosomal class a $\beta$ lactamases of Raoultella (formerly Klebsiella) planticola and Raoultella ornithinolytica. Antimicrob Agents Chemother. 2004;48(1):305-12.

44. Khaskheli M-N, Baloch S, Sheeba A. Risk factors and complications of puerperal sepsis at a tertiary healthcare Centre. Pak J Med Sci. 2013;29(4):972.

45. Demisse GA, Sifer SD, Kedir B, Fekene DB, Bulto GA. Determinants of puerperal sepsis among post-partum women at public hospitals in west SHOA zone Oromia regional STATE, Ethiopia (institution BASEDCASE control study). BMC Pregnancy and Childbirth. 2019;19:95. https://doi.org/10.1186/ s12884-019-2230-x.

\section{Publisher's Note}

Springer Nature remains neutral with regard to jurisdictional claims in published maps and institutional affiliations.

Ready to submit your research? Choose BMC and benefit from:

- fast, convenient online submission

- thorough peer review by experienced researchers in your field

- rapid publication on acceptance

- support for research data, including large and complex data types

- gold Open Access which fosters wider collaboration and increased citations

- maximum visibility for your research: over $100 \mathrm{M}$ website views per year

At BMC, research is always in progress.

Learn more biomedcentral.com/submissions 